\title{
INFLUENCE OF IRRIGANTS ON ACCURACY OF IPEX II AND DENTAPORT ZX IN WORKING LENGTH DETERMINATION
}

\author{
Tarek Elsewify*
}

\begin{abstract}
Introduction: The aim of this study was to assess the accuracy of iPex II (NSK, Tochigi, Japan) and Dentaport ZX (Morita Co, Kyoto, Japan) electronic apex locators (EALs) in working length determination in dry condition and in the presence of the following irrigants: $0.9 \%$ saline solution ( $\mathrm{NaCl}$ ), 2.6\% sodium hypochlorite ( $\mathrm{NaOCl}$ ), and 2\% chlorhexidine (CHX).

Materials and methods: Fifteen extracted, maxillary first molars were used. The actual canal lengths (ALs) were determined. An alginate model was used to determine the electronic length using a size $15 \mathrm{~K}$-file by each EAL in different conditions. Percentage of accuracy was calculated at $\pm 0.5 \mathrm{~mm}, 1 \mathrm{~mm}$ and $1.5 \mathrm{~mm}$ tolerance level. Statistical analysis was performed using the Friedman and Wilcoxon signed rank tests at a significance level of $\mathrm{P}<.05$.
\end{abstract}

Results: Results revealed a non-significant difference between the ALs and the electronic lengths (ELs) of both EALs among different canal conditions. Also a non-significant difference was shown between both EALs among different canal conditions.

Conclusions: Both EALs are shown to be accurate in WL determination among different canal conditions.

Key words: apex locator, iPex II, Dentaport ZX, irrigants, working length

\section{INTRODUCTION}

Working length (WL) determination during root canal treatment is a critical step ${ }^{(1,2)}$. The WL is best defined as the distance from a coronal reference point to the point at which canal preparation and obturation should terminate ${ }^{(3)}$. Overestimation of the WL can cause damage to the periapical tissues delaying healing. On the other hand, underestima- tion will lead to insufficient cleaning of the root canal space prevent healing as well. Radiographic method for WL determination cannot locate the exact position of the apical constriction or major fora$\operatorname{men}^{(4-5)}$. Moreover, radiographic picture is only a two-dimensional projection of a three-dimensional object. Superimposition of structures might obscure identification of the radiographic apex. Electronic

* Lecturer, Endodontic Department, Faculty of Dentistry, Ain Shams University, Cairo, Egypt 
apex locators (EALs) are shown to be more accurate in WL estimation than radiographs ${ }^{(6)}$.

In 1918, Custer first proposed electronic devices usage for WL determination ${ }^{(7)}$. In 1942, Suzuki developed the first EAL ${ }^{(8)}$. First generation EALs were resistance-based whereas second generation ones were impedance-based; both of which showed inaccuracy with electrolytes. Therefore, thirdgeneration EALs, such as Root ZX (J Morita Corp, Tokyo, Japan) were then introduced using the "ratio" method. It measures the impedance values at two frequencies $(8 \mathrm{KHz}$ and $0.4 \mathrm{KHz})$ simultaneously and then calculates a quotient that expresses the position of the file tip in the canal (9). Dentaport ZX is considered to be the gold standard against which newer EALs are evaluated ${ }^{(10)}$. iPex II (NSK, Tochigi, Japan) is claimed to be a fourthgeneration apex locator that measures capacitance and resistance simultaneously.

In vitro or ex vivo models use electroconductive materials to simulate clinical conditions. Alginate, agar, saline, and gelatin have been shown to give predictable results when used with EALs (11). Precision of electronic WL measurement depends on the EAL used and the type of irrigant ${ }^{(12)}$.

To the best of our knowledge, no published data have evaluated the influence of different irrigants on the accuracy of the iPex II EAL. The purpose of this study was to assess the effect of different irrigants on the accuracy of iPex II and Dentaport ZX in WL determination in vitro.

\section{MATERIALS AND METHODS:}

Fifteen extracted, maxillary molars were selected. Roots with resorption, cracks, fractures, or immature apices were excluded. Calculus was removed with hand instrumentation and teeth were stored in saline $(\mathrm{NaCl})(0.9 \%)$ till use.

Flattening of the occlusal surface was done using a diamond disc to provide a constant reference point for measurement. Palatal canals only were used for this study. Canal negotiation and instrumentation was done till size $15 \mathrm{~K}$-file (Dentsply Maillefer, Ballaigues, Switzerland), and apical patency was checked with a size $10 \mathrm{~K}$-file (Dentsply Maillefer). Then, the canals were irrigated with $2.5 \mathrm{~mL} 2.6 \%$ sodium hypochlorite $(\mathrm{NaOCl})$.

The actual lengths (ALs) were determined by visualization of the file tip under a dental operating microscope (Leica, Leica Microsystems, China) with a magnification of $8 \mathrm{X}$. The length was measured to the nearest $0.05 \mathrm{~mm}$ with a caliper.

Teeth were embedded in an alginate model. Resinous cast was filled with alginate impression material and teeth were immersed in it before setting. One lip clip was immersed in the alginate before setting and the file holder was attached to K-file\# 15.

Electronic lengths (ELs) measurements were obtained immediately after alginate setting by each EAL according to the manufacturer's recommendations in dry conditions and in the presence of $2.6 \% \mathrm{NaOCl}, 0.9 \% \mathrm{NaCl}$, and $2 \%$ chlorhexidine using a size $15 \mathrm{~K}$-file. Each canal was irrigated with distilled water and dried with paper points between measurements.

Accuracy percentage was calculated at $\pm 0.5 \mathrm{~mm}$, $\pm 1 \mathrm{~mm}$ and $\pm 1.5 \mathrm{~mm}$ tolerance level.

\section{Statistical analysis}

Statistical evaluation was performed using XLSTAT for Microsoft Excel (version 2018). Friedman and Wilcoxon signed rank tests were used to analyze the data. The level of significance was set at $\mathrm{P}<.05$.

\section{RESULTS}

The mean and the standard deviation of the $\mathrm{AL}$ and the EL of both apex locators among different canal conditions are shown in Table 1 . There was 
no significant difference shown among the different canal conditions using both EALs. Also a nonsignificant difference was shown between the EL and AL using both EALs among different irrigants. Although the Dentaport ZX appeared to be more accurate especially in the dry canal condition; yet, the difference was shown to be statistically nonsignificant.

Accuracy percentage within a tolerance of \pm 0.5 $\mathrm{mm}, \pm 1 \mathrm{~mm}, \pm 1.5 \mathrm{~mm}$ for both apex locators tested among different canal conditions are shown in tables 2-5 and figure 1.

TABLE (1) The mean and the standard deviation of the AL and EL of both apex locators among different canal conditions (mm)

\begin{tabular}{|c|c|c|c|c|}
\hline & Dry & Sodium Hypochlorite & Saline & Chlorhexidine \\
\hline Dentaport ZX & $21.4 \pm 0.5732^{\mathrm{a}}$ & $21.4 \pm 0.5732^{\mathrm{a}}$ & $21.36 \pm 0.6114^{\mathrm{a}}$ & $21.36 \pm 0.5498^{\mathrm{a}}$ \\
\hline iPex II & $21.33 \pm 0.5563^{\mathrm{a}}$ & $21.33 \pm 0.5563^{\mathrm{a}}$ & $21.133 \pm 0.6114^{\mathrm{a}}$ & $21.33 \pm 0.5563^{\mathrm{a}}$ \\
\hline Actual Length & $21.4 \pm 0.5732^{\mathrm{a}}$ & & & \\
\hline
\end{tabular}

* Mean values followed by same superscript letters in the same row or column are statistically non-significant $(P \leq 0.05)$.

TABLE (2) Accuracy percentage of Dentaport ZX and iPex II in dry condition within a tolerance of \pm 0.5 $\mathrm{mm}, \pm 1 \mathrm{~mm}, \pm 1.5 \mathrm{~mm}$.

\begin{tabular}{|l|l|l|l|l|l|}
\hline & $0 \mathrm{~mm}$ & $\pm 0.5 \mathrm{~mm}$ & $\pm 1 \mathrm{~mm}$ & $\pm 1.5 \mathrm{~mm}$ & $\pm 2 \mathrm{~mm}$ \\
\hline Dentaport ZX & $100 \%$ & $0 \%$ & $0 \%$ & $0 \%$ & $0 \%$ \\
\hline iPex II & $86.60 \%$ & $13.30 \%$ & $0 \%$ & $0 \%$ & $0 \%$ \\
\hline
\end{tabular}

TABLE (3) Accuracy percentage of Dentaport ZX and iPex II using 2.6\% sodium hypochlorite within a tolerance of $\pm 0.5 \mathrm{~mm}, \pm 1 \mathrm{~mm}, \pm 1.5 \mathrm{~mm}$.

\begin{tabular}{|l|l|l|l|l|l|}
\hline & $0 \mathrm{~mm}$ & $\pm 0.5 \mathrm{~mm}$ & $\pm 1 \mathrm{~mm}$ & $\pm 1.5 \mathrm{~mm}$ & $\pm 2 \mathrm{~mm}$ \\
\hline Dentaport ZX & $100 \%$ & $0 \%$ & $0 \%$ & $0 \%$ & $0 \%$ \\
\hline iPex II & $86.60 \%$ & $13.30 \%$ & $0 \%$ & $0 \%$ & $0 \%$ \\
\hline
\end{tabular}

TABLE (4) Accuracy percentage of Dentaport ZX and iPex II using 0.9\% saline within a tolerance of \pm 0.5 $\mathrm{mm}, \pm 1 \mathrm{~mm}, \pm 1.5 \mathrm{~mm}$.

\begin{tabular}{|l|l|l|l|l|l|}
\hline & $0 \mathrm{~mm}$ & $\pm 0.5 \mathrm{~mm}$ & $\pm 1 \mathrm{~mm}$ & $\pm 1.5 \mathrm{~mm}$ & $\pm 2 \mathrm{~mm}$ \\
\hline Dentaport ZX & $93.30 \%$ & $6.60 \%$ & $0 \%$ & $0 \%$ & $0 \%$ \\
\hline iPex II & $66.60 \%$ & $26.60 \%$ & $6.60 \%$ & $0 \%$ & $0 \%$ \\
\hline
\end{tabular}

TABLE (5) Accuracy percentage of Dentaport ZX and iPex II using 2\% chlorhexidine within a tolerance of $\pm 0.5 \mathrm{~mm}, \pm 1 \mathrm{~mm}, \pm 1.5 \mathrm{~mm}$.

\begin{tabular}{|l|l|l|l|l|l|}
\hline & $0 \mathrm{~mm}$ & $\pm 0.5 \mathrm{~mm}$ & $\pm 1 \mathrm{~mm}$ & $\pm 1.5 \mathrm{~mm}$ & $\pm 2 \mathrm{~mm}$ \\
\hline Dentaport ZX & $93.30 \%$ & $6.60 \%$ & $0 \%$ & $0 \%$ & $0 \%$ \\
\hline iPex II & $86.60 \%$ & $13.30 \%$ & $0 \%$ & $0 \%$ & $0 \%$ \\
\hline
\end{tabular}




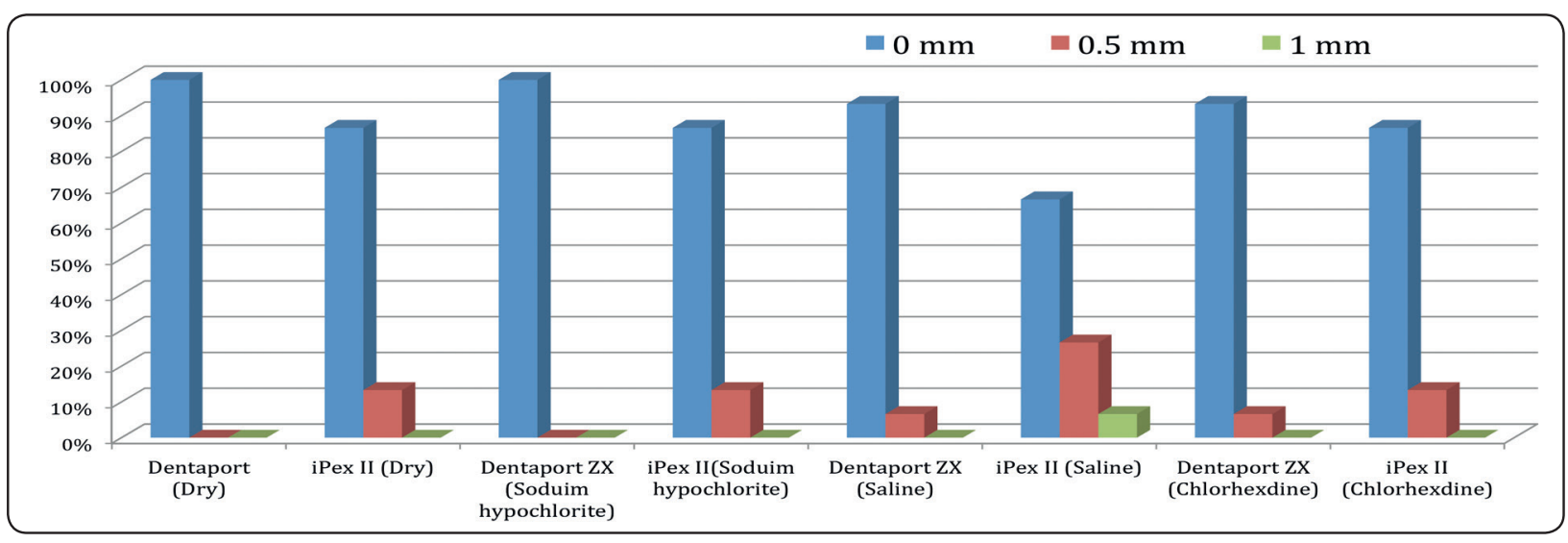

Fig. (1) Accuracy percentages of all groups at \pm 0.5 - $\mathrm{mm}$ and $1 \mathrm{~mm}$ tolerance level.

\section{DISCUSSION}

Numerous in vitro and in vivo studies have been conducted to determine the accuracy of EALs. Most of the EALs showed a high-degree of accuracy in WL measurement ${ }^{(13,14)}$. The major foramen ${ }^{(13)}$ or the minor foramen ${ }^{(15)}$ is used in vitro studies as the apical reference point. Yet, the major foramen could be a more reproducible reference point for in vitro studies ${ }^{(16)}$.

In the current study, an alginate model was used as previously described by Kaufman et al. ${ }^{(17)}$. Alginate has electrical impedance that imitates the human periodontium, can be used for in vitro assessments of EALs ${ }^{(18)}$ and can also be used with any irrigation solution ${ }^{(19)}$. It is accurate, easy to use and reliable ${ }^{(19)}$ as its construction required no special materials other than heat cured acrylic resin and alginate impression material. This model could provide service up to 24 hours without bias. The validity of this model for its application in research was tested, as accuracy studies using radiographs and SEM have been well documented ${ }^{(20)}$. Measurements were done immediately after setting of the alginate.

Results of an in vitro study may raise doubts about its clinical relevance. Some previous studies indicate that, even in fully controlled in vitro study conditions, there is some inconsistency in EAL measurements ${ }^{(21)}$. It should be emphasized that the results obtained in this in vitro study cannot be directly extrapolated to the clinical situation, but can provide an objective examination of a number of variables that are not practical to test clinically.

The literature shows conflicting results regarding the effect of irrigants on EALs. Results of the present study came in full agreement with those of Kaufman and Li in which the irrigants used did not affect the accuracy of different EALs tested ${ }^{(22,23)}$. Marigo et al (24) found that the accuracy of the Dentaport ZX was not affected by sodium hypochlorite. Duran-Sindreu et al ${ }^{(25)}$ also showed that sodium hypochlorite had no effect on the accuracy of the Root ZX and the iPex. Stöber et al. (26) also observed no significant differences between the iPex and Root ZX devices using $2.5 \%$ sodium hypochlorite. On the other hand, Venturi and Breschi (27) revealed unstable measurements for the Root ZX in dry canals. Kaufman et al ${ }^{(17)}$ also showed the Root ZX to be more accurate in the presence of EDTA and saline than in dry canals. However, in our study, the Dentaport ZX and the iPex II were not affected by the canal condition.

Minor and major foramen morphology together with the location of the major foramen are three important factors influencing the accuracy of EALs 
$(27,28,29,30)$. Stein et al. ${ }^{(28)}$ reported that the accuracy of EALs depends to a great extent on the major foramen diameter. Others have observed that the accuracy of EALs varies depending on the minor foramen diameter ${ }^{(30,31)}$. Therefore, the different results from different studies could be attributed partly to the nature of teeth used.

Tolerance of $\pm 0.5 \mathrm{~mm}$ was used in many studies

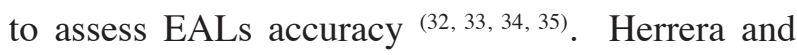
others used a more lax range of $\pm 1.0 \mathrm{~mm}^{(31)}$. Results within these ranges are considered accurate and clinically acceptable. In our study, all the results fall in this range and thus are considered acceptable.

Comparison of the standard deviation is helpful for assessing reliability of EALs. If the EAL measurements are consistent, a low standard deviation is obtained. In our study, standard deviations were nearly equal for both EALs among all canal conditions.

\section{REFERENCES}

1. Ricucci D. Apical limit of root canal instrumentation and obturation, part 1. Literature review. Int Endod J 1998;31:384-93.

2. Ricucci D, Langeland K. Apical limit of root canal instrumentation and obturation, part 2. Histological study. Int Endod J 1998;31:394-409.

3. Glossary of endodontic terms. 7th ed. Chicago: American Association of En dodontists;2003.

4. ElAyouti A, Weiger R, Lost C. Frequency of overinstrumentation with an acceptable radiographic working length. J Endod 2001;27:49-52.

5. Tselnik M, Baumgartner JC, Marshall JG. An evaluation of Root ZX and Elements Diagnostic Apex Locators. J Endod 2005;31:507-9.

6. Cianconi L, Angotti V, Felici R, Conte G, Mancini M. Accuracy of three electronic apex locators compared with digital radiography: an ex vivo study. J Endod 2010;36:2003-7.

7. Custer LE. Exact methods of locating the apical foramen. J Natl Dent Assoc 1918;5: 815-9.
8. Suzuki K. Experimental study on iontophoresis. J Jap Stomatol 1942;16:411.

9. Kobayashi C, Suda H. New electronic canal measuring device based on the ratio method. J Endod 1994;20:111-4.

10. de Vasconcelos BC, do Vale TM, de Menezes AS, et al. An ex vivo comparison of root canal length determination by three electronic apex locators at positions short of the apical foramen. Oral Surg Oral Med Oral Pathol Oral Radiol Endod 2010;110: e57-61.

11. Gordon MP, Chandler NP. Electronic apex locators. Int En$\operatorname{dod} \mathrm{J} 2004 ; 37: 425-37$.

12. Tsesis I et al. The Precision of Electronic Apex Locators in Working Length Determination: A Systematic Review and Meta-analysis of the Literature J Endod 2015;41:18181823

13. Guise GM, Goodell GG, Imamura GM (2010) In vitro comparison of three electronic apex locators. Journal of Endodontics 36, 279-81.

14. Plotino G, Grande NM, Brigante L, Lesti B, Somma F. Ex vivo accuracy of three electronic apex locators: Root ZX, Elements Diagnostic Unit and Apex Locator and ProPex. International Endodontic Journal; 2006, 39, 408-14.

15. Ibarrola JL, Chapman BL, Howard JH, Knowles KI, Ludlow MO. Effect of preflaring on Root ZX apex locators. Journal of Endodontics;1999, 25, 625-6.

16. Venturi M, Breschi L. A comparison between two electronic apex locators: an in vivo investigation. International Endodontic Journal; 2005, 38, 36-45.

17. Kaufman A.Y., Keila S., Yoshpe M.: Accuracy of a new apex locator: an in vitro study. Int Endod J;35:186 -92, 2002.

18. Baldi J.V., Victorino F.R., Bernardes R.A.: Influence of embedding media on the assessment of electronic apex locators. J Endod; 33:476 -9, 2007.

19. Kaufman A.Y., Katz A.: Reliability of Root ZX apex locator tested by an in vitro model. J Endod; 19:201, 1993.

20. Kumar S.S., Chacko Y. and Lakshminarayanan L.: A simple model to demonstrate the working of electronic apex locators. Endodontology; 16, 50-53, 2004.

21. Ebrahim AK, Wadachi R, Suda H.: Accuracy of three different electronic apex locators in detecting simulated horizontal and vertical root fractures. Aust Endod J; 32:64 -9, 2006. 
22. Kaufman AY, Fuss Z, Keila S, et al. Reliability of different electronic apex locators to detect root perforations in vitro. Int Endod J 1997;30:403-7.

23. Li YH, Zhou Z, Zheng YQ, et al. Accuracy of three different electronic apex locators in determination of perforation with various conditions in vitro. Hua Xi Kou Qiang Yi Xue Za Zhi 2011;29:272-5.

24. Marigo L, Gervasi GL, Somma F, et al. Comparison of two electronic apex locators on human cadavers. Clin Oral Investig 2016;20:1547-50.

25. Duran-Sindreu F, Gomes S, Stober E, et al. In vivo evaluation of the iPex and Root ZX electronic apex locators using various irrigants. Int Endod J 2013;46:769-74.

26. Stöber EK, Duran Sindreu F, Mercadé M, Vera J, Bueno R, Roig M. A evaluation of Root ZX and iPex Apex Locators: an in vivo study. Journal of Endodontics, 2011:37, 607-10.

27. Venturi M, Breschi L. A comparison between two electronic apex locators: an ex vivo investigation. Int Endod J 2007;40:362-73.

28. Stein TJ, Corcoran JF, Zillich RM. Influence of the major and minor foramen diameters on apical electronic probe measurements. Journal of Endodontics;1990, 16, 520-2.

29. Pagavino G, Pace R, Bacceti T. A SEM study of in vivo accuracy of the Root ZX electronic apex locator. Journal of Endodontics;1998, 24, 438-41.

30. Ding J, Gutmann JL, Fan B, Lu Y, Chen H. Investigation of apex locators and related morphological factors. Journal of Endodontics; 2010, 36, 1399-403.

31. Herrera M, Abalos C, Planas AJ et al. Influence of apical constriction diameter on Root ZX apex locator precision. Journal of Endodontics; 2007, 33, 995-8.

32. Caliskan MK, Kaval ME, Tekin U. Clinical accuracy of two electronic apex locators in teeth with large periapical lesions. Int Endod J 2014;47:920-5.

33. Khandewal D, Ballal NV, Saraswathi MV. Comparative evaluation of accuracy of 2 electronic apex locators with conventional radiography: an ex vivo study. J Endod 2015;41:201-4.

34. Milanovic I, Ivanovic V, Vujaskovic M, et al. Accuracy of three electronic apex locators in determining the apical foramen in multi-rooted teeth: randomised clinical and laboratory study. Aust Endod J 2015;41:35-43.

35. Connert T., Judenhofer M., Hulber-J M., Schell S., Mannheim J., Pichler B., Lost C. and ElAyouti A.: Evaluation of the accuracy of nine electronic apex locators by using Micro-CT. International Endodontic Journal, 51, 223-232, 2018. 